\title{
Towards a model and strategy for transformational change
}

\author{
Abeni El-Amin *(D, Babu George **(D) \\ ${ }^{*}$ Fort Hays State University, Hays, Kansas, USA \\ ** Christian Brothers University, Memphis, TN, USA \\ E-mail:aelamin@fhsu.edu; bgeorge@cbu.edu
}

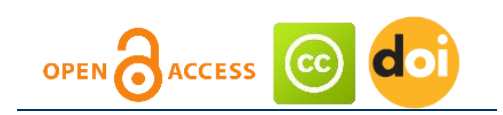

Article history:

Received: May 12, 2020

1st Revision: August 12, 2020

Accepted: October 30, 2020

\section{JEL classification: \\ L16 \\ 033 \\ R11}

\section{DOI:}

10.14254/jems.2020.5-2.2

\begin{abstract}
Leaders must ask critical questions when deciding to initiate change such as: Where to begin? What and how to organize resources? How to distribute responsibilities within the organization? These questions are especially important when an organization faces the need to change in the instance of a crisis. Leaders must develop objectives, which accomplish strategic goals. Logically, these goals categorize into explicit actions: the organization should clarify how they sequence and correlate a change strategy. Articulating precisely which capacities, structures, and product offerings influence how stakeholders perceive change within organizations is vital. This article sketches key processes and pathways that make transformational change possible.
\end{abstract}

Keywords: leadership, decision making, change, strategy, stakeholder development.

\section{Introduction}

When leaders focus on leadership excellence, they understand the objective of permanent, manageable change (Gilley, Dixon, \& Gilley, 2008). Moreover, a typical timetable of three to five years is the average for organizational transformation, which may appear prima facia to be unreasonable, but change takes time (Kotter, 2012). Organizational change goals, just as nuances and activities, are a portrayal of what the organization resembles at different stages along the way. Additionally, articulating goals is mandatory for two reasons. From one perspective, internal and external stakeholders need communication about the substantial and explicit manner of the change strategy. Exemplary communication causes staff to envision the path forward and to take responsibility for explicit targets, and it eases tension (Isern \& Pung, 2007). In conclusion, leaders must be both goaloriented and practical, while understanding that marginal goals speak to an approach to solve longterm issues within organizations (Kotter, 2012). Illuminating changes in a progression helps to identify future targets from both quantitative and subjective measures.

The future of leadership requires flexibility and adaptation to change management frameworks. Additionally, aligning the value of leadership to organizational goals is an emerging

Corresponding author: Babu George

E-mail: bgeorge@cbu.edu

This open access article is distributed under a Creative Commons Attribution (CC-BY) 4.0 license. 
need in the promotion of leadership (Barsh, Capozzi, \& Davidson, 2008). There is a dichotomy between innovative leadership agendas and traditional leadership initiatives. For instance, Uhl-Bien and Arena (2018) expanded the research on leadership evaluation from a strategic management perspective. They examined whether the use of the organizational methodology approach can enable effective delivery of leadership strategies, thus strengthening the link between leadership and organizational goals. Action research methodology is the base of the research. The research findings indicated that organizational methodologies allow visualization of a clearly focused and internally consistent map of cause and effect relationships. Turning practical leadership efforts into strategic results, while adequately supporting leadership functions both in managing leadership processes and in delivering targeted organizational outcomes is the mark of constructive leadership. Offering a specific set of critical measures for evaluating leadership performance, and permits the fostering of alignment between leadership program objectives and functional goals.

Change management initiatives must accommodate adherents or followers based on organizational capabilities and chosen a change management framework. Leaders should utilize a multitude of change management activities and provide adherents or followers with assistance as they become more proficient using change management processes (i.e., Kotter's Eight Steps or Lewin's Theory of Planned Change) (Kotter, 2012; Shirey, 2013). These frameworks and models offer valid explanations of why leading with one style is counterintuitive. The use of one or more change management style instruments should be given to adherents or followers so leaders can better develop their change management strategy. Change management style instruments help adherents, and other stakeholders consider the depth of change management possibilities.

Extant literature on leadership and change presents a coherent set of strategies to lead transformational change. It begins by highlighting the role of vision as something setting the scene for a change. Then, the role of servant leadership as a change agent and the roles of training and development as change enablers present opportunities for reflection. With these as the basis, a model for transformational change management and strategies for implementing change ensues.

\section{Setting the scene for change}

To remain a salient competitor in business, organizations must adjust quickly to changing business conditions (Kotter, 2012). Thus, change management assumes an important function, which organizations and professionals regularly apply to organizational change initiatives when planning and executing change endeavors. Similarly, resistance from change creates a positive perspective, which implies that it is considered an opportunity as opposed to a hindrance (Solano \& Preuß, 2019). Consequently, this adjusted change model conception incorporates leadership approaches disregarded in Kotter's change models. For instance, novel leadership communication strategy is distinct among female and male leaders, which indicates differences in how vision ensues communicative form during the process (Şahin, Gürbüz, \& Şeşen, 2017). Out of this knowledge, an alternative or coinciding change model to that of Kotter (2012) deals with the dynamics of leadership.

Regardless of how a leader proceeds with change management, the process of change needs a verified model to make a needed change within an organization. As a result, present change management frameworks for small to medium enterprises (SMEs), utilize existing frameworks in light of professional endorsement from logical perspectives in effectively dealing with change management programs (Rajan \& Ganesan, 2017). Likewise, suggestions for improving this framework expand the knowledge of change management leaders and practitioners across various business types concerning communicating the vision for change. Propositions to improve upon this model include making comparable analyses across various organizations and noting how other leaders execute their change management initiatives.

The outcomes recommended indicating that there must be a need for change, which intercedes the connection between leadership vision and organizational development (Haque, TitiAmayah, \& Liu, 2016). Likewise, there is an immediate effect of how leaders communicate the need for change and subsequent actions to initiate change within organizational development strategy. Initially, the need for change may not necessarily connect with organizational development or the connection between vision communication at the time. Yet, it is how leaders begin the discussion leading to the implementation of change initiatives that makes the process easier. From a theoretical perspective, dissecting the connection between organizational vision and the need for organizational change enhances the command of leaders within the organizational change process, and this way improves 
organizational execution and development. Moreover, the significant role of employees' support within the change process is an invaluable asset to attain organizational goals.

In perspective, Kotter's (2012) methodology provides guiding principles about how transformational leaders can execute change within organizations. Primarily, individuals and the procedural parts of change become the dominant focal point within a change management strategy; a need for change disrupts the status quo within the organization, and individuals need to be part of the change process for change to be sustainable (Page \& Schoder, 2019). By including others, commitment and empowerment expand the ability of leaders to make lasting change. Last, a change lasts in the event when linked with organizational structures and strategy.

The importance of providing vision in an organization means to communicate information regarding education strategy to stakeholders. It can be challenging for leaders to be transparent when communicating with stakeholders and clients because some information is too complicated. Yet, leaders much find a way to connect to their followers. Moreover, while email or virtual technology has its benefits, it's not the best communication method. There are times when a leader must provide personal interaction to rally support. Person-to-person presentations are the most effective manner to communicate (Markovic \& Salamzadeh, 2018). Regarding a change management strategy, the leader's role is of great importance in inspiring stakeholders and creating a productive working environment (Kotter, 2012). Utilizing vision initiatives and assessing organizational issues in context are viable mechanisms to improve interactions in organizations.

Creating a vision is about directing support to galvanize one's initiatives. Finding ways to encourage others inspires the vision as visions provide a framework of what the future holds for the organization (Kotter, 2012). Creating a vision that is relatively simple to convey offers stakeholders an efficient way to process concepts. Most importantly, stakeholders cannot grasp onto a vision they do not understand. Visions developed with a long-term strategic focus are a key indicator or performance. A vision communicates the direction an organization needs to take. In doing so, the vision develops by a leader. Visions are developed over time, using a methodological approach (Kotter, 2012). Without a reasonable vision, mismanaged organizational resources become the norm, stakeholders become confused about the direction of the organization, and initiatives of the organization tend to fail or become unsustainable (Chappell, Pescud, Waterworth, Shilton, Roche, Ledger, \& Rosenberg, 2016). In failed organizations, there are often several plans, proposals, and programs; however, a formulated vision has yet to occur. The overall objective must be to provide the team with a vision of how their cumulative efforts result in success.

\section{Barriers to organizational change}

There exists a gap in leadership knowledge of how to execute change management initiatives (Easdale, 2001). From this perspective, there appears to be a decay in social capital (Putnam, 2012). Analyzing the organization between business leadership style and consequences for social capital spotlights on leadership advancement. Servant leadership as a leadership style may influence social capital (Greenleaf, 1970). Articulation is a technique in which four principle practices connect different viewpoints of servant leadership: leadership style, community, service, and how power is exercised (Easdale, 2001). Finally, outcomes demonstrate that an organization that constructs social capital, both internally and externally, serves the most important needs of its staff while additionally impacting its external alliances.

Moreover, people resist change because of the fear of the unknown. Some leaders experience that driving change fast creates confusion and anxiety. To learn about an organization, new leaders must ask questions to extant stakeholders and chart plans in 18-24 months or more instead of 6-12 months. In the end, as a leader, the most important lessons is what difference if a change takes place in 6 months or 24 months if there is no exacting need? The most important vehicle is building community, trust, and lasting change. A quickly contrived or innovative change falls short if a leader's stakeholders' are not on board as they resist change, and generally, the organizational environment becomes shaded by ambition, instead of service

Organizations have found innovative ways to mitigate and/or counter staff and volunteer resistance to organizational or program changes by reducing or streamlining processes to accomplish more effective work across teams and departments. For example, agencies establish improved volunteer processes such as volunteer on-boarding, post-hire evaluations/meetings, and train/re-training. Aspects such as these are incorporated to inspire a renewed energy for organization-volunteer relations. Likewise, incorporating a Mentorship Program to acclimate new 
volunteers to organizational climate properly is ideal. Additionally, processes added to hold stakeholders (administration, staff, volunteers, Board Members) accountable to volunteer initiatives increase connective organizational culture. These processes are often different from what some organizations have done in the past, so this different manner of doing things takes time to organize and accept by stakeholders of the organization. Last, the most inspiring story of successful change is when there is buy-in from stakeholders.

Blanchard (2018) indicated that the change process has four distinct stages: discovery, immersion, alignment, and refinement. Besides, critical success factors for cultural transformation are acknowledged by organizations that effectively develop high performing, values-adjusted organizations and propose five fundamental success factors. For instance, senior leadership must exhibit the senior leadership group must advocate a commitment to the long-term process as the change process culture. Leaders are held to high standards as the qualities are characterized and imparted by them. Cultural transformation is a systematic endeavor that never changes as leadership sets the stage to embrace an innovative organizational culture. Organizational culture is the critical process that makes desired practices observable, tangible, and measurable; Responsibility for conveying guaranteed performance practices is fundamental. The results must be quick and consistent. Positive ramifications for meeting execution and qualities requirements extol interpretation, demonstration, and establishment based upon adverse outcomes. Results must be applied when implementation is below standards or esteemed practices not exemplified.

It is crucial that all staff who are associated with and buy-in to change management strategies at each stage. This process need not be linked with management by announcements, where leaders communicate new directions yet do not welcome feedback from staff. For staff to envision the ideal culture, they should be part of the process. Staff should help depict and apply what the new culture demands of them in their roles; Change must coincide with management initiatives in the scope of change activities. Most importantly, leaders must not attempt to change the whole organization at one time. They should begin with a distinct part of the organization (an office, division, plant, or local office) to figure out how the process flows. At that point, because of knowledge gained, they may choose another part of the organization, and lead the change process until all parts of the organization change.

Servant leadership is a widely accepted leadership style (Blanchard, 2018). While an instinctively exciting idea, it is methodically indistinct and not yet supported by present research (Cinite \& Duxbury, 2018). Servant leadership is a hypothetical structure that executed to develop influential organizations. This development is necessary for classifying and assessing the practical nature and qualities of servant leaders. When well-organized, a progressive servant leadership quality model evolves (Russell and Stone, 2002).

Further, Cinite and Duxbury (2018) demonstrated that staff most often resist change by voicing their concerns about change. Second, the staff who are focused on the change are most likely to voice their concerns to their superiors within the chain of command.

\section{Change that serves, get their support: Servant leadership as change agent}

Greenleaf defined the servant-leader as follows: "The servant-leader is servant first... It begins with the natural feeling that one wants to serve, to serve first." Greenleaf (1970). Meanwhile, Greenleaf portrayed a way of thinking, not a hypothesis. In any case, in light of the perspectives of various practitioners, the components that are nuanced to servant leadership are contrasted. Different hypotheses contend moral aspects, not just regarding individual morality and propriety of the servant-leader, but by how a servant-leader empowers improved moral behavior among their adherents. In this manner, test the moral premise of the servant-leader's visions and organizational goals. The focus on serving supporters to their benefit, not merely the good of the organization, and framing long-term associations with devotees, empowering their development and advancement are goals of servant leaders. Achieving leadership potential requires servant leaders who are concerned with the success of all stakeholders, broadly defined; 'employees, customers, business partners, communities, and society as a whole, including those who are the least privileged. Self-reflection,' as a counter to the leader's ego or self-confidence, develops out of the need to support stakeholders (Greenleaf, 1970).

Servant leadership, a conjectured leadership model where the moral ethics of humility coincides with interest-driven conduct. Sousa and van Dierendonck (2017) postulated an analysis that determined how these two paradoxical aspects of servant leadership interact in generating 
adherent engagement while considering the hierarchical power of the leader as a contingency variable. They found that unassuming leaders demonstrated the most empowering effects on adherent commitment regardless of their position. Less unassuming leaders in lower leveled positions can compensate through a resilient action-oriented leadership style. Most eminently for leaders in hierarchical positions, humility appears to reinforce the impact of their behavior as actionoriented leaders the most. These findings offer an understanding of the transaction between the moral ethics of humility and the action-oriented practices of servant leaders (Sousa \& van Dierendonck, 2017).

Further, while applying servant leadership, it has two aspects: vision and implementation. In the visionary role, leaders typify the direction. They must outline and convey organization needs (Blanchard, 2018). Next, the implementation stage is categorized by purposeful conduct to drive servant culture. Subsequently, great leaders urge adherents to bring their full being to work as implementation is impacted the most. Two types of leadership develop strategic leadership and operational leadership (Blanchard, 2018).

Strategic leadership is the "what" that guarantees everybody is going in a similar direction. It is a response to the inquiry, "What is the purpose of the business?" Strategic leadership incorporates action, to develop a definite vision, maintaining a culture adapts its qualities to that vision, and communicating activities or strategic imperatives the organization needs to achieve. Strategic leadership is about the vision and direction aspect of servant leadership (Blanchard, 2018). Also, operational leadership is everything else. It gives the "how" for the organization. It incorporates the approaches, strategies, frameworks, and leadership practices that progress from senior leadership to staff. These leaders create an environment that staff and clients associate with and react to consistently. Operational leadership is about the execution aspects of leadership or the servant part of servant leadership.

Additionally, being a servant leader is an issue of the heart. Servant leaders lead with hearts encouraged without self-interest of motivation, security, and status. Leaders delight in the success of those around them.

While some leaders are driven, others are called into leadership. Self-serving leaders surface in two different ways (Blanchard, 2018). The first is how they gain feedback. A subsequent indication is that self-serving leadership is reluctant to develop different leaders around them. They fear the potential rivalry for their leadership position. Though called leaders have hearts of a servant, and they welcome feedback. They know they are driven to serve, and if anyone has recommendations on how leaders can serve better, they want to hear them. They receive this input as a blessing. Servant leadership is about taking individuals from one position to the next. The significance of having a convincing vision cannot be underestimated. When a practical vision is developed, goals and procedures can be formed to establish the vision. Transformational leadership endeavors emerge from self-leadership to one-on-one leadership, to group leadership, to organizational leadership. As a leader, when the vision and direction are set, they need to flip the hierarchical pyramid and focus on goals as defined by the vision. Finally, trust is fundamental to the leader-follower relationship. Trusting leaders empower adherents, which can lead to a more significant commitment to the organization and the leader (Davis, 2017).

Professionals must continuously reinvent themselves; continuous improvement is necessary for professionals as changing business demands require professionals to stay current with the latest industry knowledge. Dean and Bowen (1994) conveyed that knowledge acquisition could be enhanced by incorporating some insights into continuous improvement into management theory. Moreover, management practice could be improved by incorporating continuous improvement to improve leadership training and development initiatives. More professionals should incorporate continuous improvement theory into career plans. In the field of educational leadership, compliance and regulation require leaders to stay informed of regulatory and budgetary policies affecting institutions. Just as the information is essential, so is the training necessary to execute policies. In this light, institutions must ensure that leaders have the support needed to acquiesce.

Incorporating leadership principals lends to the overall notions of why servant leadership is an excellent management tool. As such, servant leadership constitutes a contemporary instructive theory of leadership, which emphasizes the use of the heart in professional practices, as such, the follower-leader interaction both internally and externally and within the organization (Gandolfi \& Stone, 2018). Using the heart is essential in communication to build rapport and trust with others. Heart-based communication is deeply rooted by the emphasis on other fields and cognitive disciplines that embrace servant leadership (Abu Bakar \& McCann, 2016). Servant leadership 
execution is respected by followers, is an impetus for collaboration, and is progressive as a management tool. In practice, providing followers with a servant leader in organizations engages follower motivation. Organizations that include servant leadership practices become alive with spirit when followers incorporate servant leadership culture into their daily work.

\section{Training and development as change enablers}

If servant leadership is a significant change agent, training and development are also equally essential to change management. Making the change sustainable is espoused via an emphasis on training and development. As such, pragmatic learning methodologies should be considered when developing organizational change management training. Scaffold and Eddy (2006) presented the idea of an organizational change management methodology to utilize andragogy. Organizational training and development benefits are that it differs from traditional learning methodologies. Organizational change management is an articulation of what needs to be assessed and altered within an organization. As a result, organizational change management can be used in most disciplines (Kasworm, Rose, \& Ross-Gordon, 2010). Organizational change management learning methodologies offer some valuable learning approaches, such as the utilization of various engagement applications such as apps, slide decks, video, mp3, mp4, sound bites, graphic designs, and e-learning (Binkley, Erstad, Herman, Raizen, Ripley, Miller-Ricci, \& Rumble, 2012; Steiner, Albert, \& Heller, 2007).

While incorporating dynamic learning methodologies is an additional facet to creating engaging presentations, one must evaluate the significance of utilizing a variety of learning methodologies in organizational change management. While a majority of surveys affirm the satisfaction of training and development in different organizations, there is debate regarding the full utilization of information after a training program (Steiner, Albert, \& Heller, 2007). For example, the selection of learning methodologies in organizational change management imparts adequacy of training content to improve employee's capabilities. Additional benefits of training and development are assisting organizations in comprehending the skills of instructors in engaging employees in learning. Training and development offer instructors alternative and adaptable instructional methods, which are highly valuable with different learning styles (Cheng, Wang, Yang, \& Peng, 2011). While innovation can empower employees and instructors, adaptable instructional methods are supported and expressed through innovative practices.

When planning for training effectiveness, financial, cultural, and social changes experienced by organizations determine training and development procedures in change management endeavors. In progressive working environments, the abilities and skills of employees can quickly become obsolete, and thus, employees must consistently train to maintain competitiveness in the global organization. On the other hand, traditional models of training and development both inside and outside of the organization environment have created inconsistent organizational change management practices. Before the advent of systematic training and development practices in employee development programs, unfocused training environments were the norm (Billett, 2010). Moreover, these aspects of the training were unorganized. Little focus on the overall mission of the organization or consideration of the employee's capabilities past their existing roles often occurs. As such, these environments create versatile training programs, useful, and epistemologically sound practices.

Halverson and Sheridan (2014) portrayed the underlying foundations of the development of formal training and development methods. Moreover, the Human Resource Manager's (HRM) goal is to provide managerial execution through training and development practices and management of organizational information. HRM methodologies result in better training through training and development, leadership advancement, and adds to accomplishing leadership execution (Halverson \& Sheridan, 2014). Leadership support for training and development programs enhances its ability to improve human resource capacity. Leadership development adds to the foundation of improvement; therefore, employment organizations should utilize organizational change management to improve training standards. These findings are particularly valuable for executives, HRM managers, and training departments (Kuo, 2011). Further, innovative organizational change management curriculum design utilizes tools to engage audiences. Notwithstanding, the role of training and development in change management programs establishes permanency because employment training develops leadership skills in employees, while simultaneously provides evaluation metrics to demonstrate training effectiveness within change management initiatives (Greller \& Drachsler, 2012; Manuti, Pastore, Scardigno, Giancaspro, \& Morciano, 2015). 


\section{Transformational change management}

Each organization is unique, and each transformation initiative different. However, the objective of any transformation is a sustainable improvement regarding a change in an organization's development. Characterizing a transformation indicates different components of leadership decisions (Kotter, 2012). It underscores, for example, the significance of improvement, establishing a platform, and profit utilization. Therefore, leaders must consider a framework to initiate organizational change. For instance, Kotter (2012) expressed an eight-step process for successful change management to create urgency, form a powerful coalition, create a vision for change, communicate the vision, remove obstacles, create short-term wins, build on the change, and anchor the changes in corporate culture. As a result, leaders must routinely consider methods of execution for organizational wellbeing.

Further, Dent and Goldberg (1999) found that one of the most generally acknowledged conceptual models that drive hierarchical performance is the possibility there is protection from change and that supervisors must be the only group responsible for the change. This psychological model is typically held by staff at all levels, interferes with effective change. The one constant is that change is persistent. Moreover, before Kotter, Kurt Lewin presented change management as a framework and a powerful mechanism for leaders and staff similarly (Woodward \& Hendry, 2004). Since the broad acceptance of a change model, professionals and academics alike have confounded the comprehension of change components. Consequently, some have gone so far as to relinquish the term change management and instead opt for less stressful terminology such as organizational development. This typifies a path for increasingly valuable models of change lexicon.

\section{Leadership strategies for transformational change}

The following five change management leadership strategies and their outcomes describe an effective process for leading change (Blanchard, 2012).

\section{Strategy 1: Expand Involvement and Influence}

(Outcome: Buy-In) By involving stakeholders in decision making about the change, leaders significantly increase the probability that the change is successfully implemented. Stakeholders are less likely to resist change when they have been involved in creating change.

\section{Strategy 2: Explain Why the Change Is Needed}

(Outcome: Compelling Case for Change) This strategy addresses information concerns. When leaders present and explain a rational reason for the change, the outcome is a compelling case that helps stakeholders understand the change being proposed, the rationale for the change, and the reason the status quo is no longer a viable option.

\section{Strategy 3: Collaborate on Implementation}

(Outcome: The Right Resources and Infrastructure) When leaders engage others in planning and piloting the change, they encourage collaboration in identifying the right resources and building the infrastructure needed to support the change.

\section{Strategy 4: Make the Change Sustainable}

(Outcome: Sustainable Results) Rather than simply announcing the change, leaders must make the change sustainable by providing stakeholders with the new skills, tools, and resources required to support the change. By modeling the behavior they expect of others, measuring performance, and praising progress, leaders create conditions for accountability and good results.

\section{Strategy 5: Explore Possibilities}

(Outcome: Options) Possibilities and options should be explored before a specific change is chosen. By involving others in exploring possibilities, you immediately lower information concerns when a new change is announced, because stakeholders are "in the loop" about deciding what needs to change. To summarize, organizations should spend more energy reinforcing the change they just made than looking for the next great change to implement. 


\section{Concluding remarks}

The change process connects theory to the field of change management. Change management acumen in the field of organizational management is an important core competency, which is derived from organizational focus and change management strategy, which enables professionals to create significant improvements in management (Webber \& Scott, 2008). As a leader in instruction and management, one will become so by creating processes to address organizational problems as well as more abstract technical issues that occur in organizations (Baltaci \& Balcl, 2017). The ability to bring innovative ideas and processes to light leads to better management of organizational initiatives (Hosseini, Kees, Manderscheid, Röglinger, \& Rosemann, 2017). As a result, core competencies learned are best utilized by conceptualizing, initiating, leading, organizing, delegating, and executing plans when necessitated.

As such, Harris (2019) contended that freedom of intellectualism is needed in organizations. Greater attention must be given to the examination of change management in organizational development. That is, staff must be provided an opportunity in the change management process to conjecture without fear of reproach. This is concurrent with change management theories within the field, which indicate that leaders should not seek to limit unpopular perspectives of staff (Harris, 2019). A good leader is open to both positive and negative critique and uses this information to make decisions. From an organizational perspective, organizations typically adopt a divisional structure (Manning, 2017). In doing so, they have created the kind of structure which provides leaders a way to systematically work through issues of each unit to sustain, improve, and develop new programs, thereby achieving organizational change (Kurtz \& Berston, 2019).

Given the sizable and complex nature of many organizations, an appreciation of how to lead in this environment is important. Therefore, as a leader, the objective is to assist the organization in succeeding in a precipitously changing environment (Thoms \& Burton, 2016). Hence, a change management mindset is critical (Ho, Salleh, \& Chua, 2019). While organizations are ultimately driven by demand, they also have to deal with economic, technological, socio-cultural, and environmental concerns. Governmental policy and global competition are also chief influences when recruiting, admitting, educating, supporting, and retaining students. As a result, the traditional roles of leaders have been redefined (Jacob \& Gokbel, 2018). Currently, the objective is to provide solutions and strategies to predict an uncertain future. Meaningful contributions are made in areas such as designing a vision for the institution, managing resources effectively and engaging in dialogues that reflect diverse viewpoints of all stakeholders to foster a spirit of advancement (Howard, O'Brien, Kay, \& O'Rourke, 2019). Keeping stakeholders engaged in the process of changing demands is vital to sustainability.

Intentional evaluation helps leaders understand organizational assets and strategic capabilities, as well as the expectations of all stakeholders. Through deliberate analysis, leaders create methodical change management plans, indicate a direction, increase the span of independence and accountability of employees, and help improve the competitiveness of organizations (Ho, Salleh, \& Chua, 2019). Certainly, the advantages of management lie in the ability of leaders to incorporate change management strategies to improve upon the capacity of organizations to work better with its stakeholders, provide excellent services, expand demand capacity, express brand awareness, and demonstrate a commitment to corporate social responsibility (CSR) (Albliwi, Antony, \& Lim, 2015). Finally, it is important to connect change management opportunities to present realities. Today's professional operates in a global environment, and the ability to apply these concepts improves the discipline of leadership.

\section{Appendix A. Supplementary material}

Supplementary data associated with this article can be found, in the online version, at https://doi.org/10.14254/jems.2020.5-2.2

\section{Citation information}

El-Amin, A., \& George, B. (2020). Towards a model and strategy for transformational change. Economics, Management and Sustainability, 5(2), 28-38. doi:10.14254/jems.2020.5-2.2. 


\section{References}

Abu Bakar, H., \& McCann, R. M. (2016). The mediating effect of leader-member dyadic communication style agreement on the relationship between servant leadership and group-level organizational citizenship behavior. Management Communication Quarterly, 30(1), 32-58.

Albliwi, S. A., Antony, J., \& Lim, S. A. H. (2015). A systematic review of Lean Six Sigma for the manufacturing industry. Business Process Management Journal, 21(3), 665-691.

Alfaro Solano, M. J., \& Preuß, M. (2019). An alternative approach on resistance to change and leadership and its resulting development of Kotter's change models.

Baltaci, A., \& Balcl, A. (2017). Complexity change management: A theoretical perspective. International Journal of Educational Change management and Management, 5(1), 30-58.

Barsh, J., Capozzi, M. M., \& Davidson, J. (2008). Leadership and innovation. McKinsey Quarterly, 1, 36.

Billett, S. (2010). The practices of learning through occupations. In Learning through practice (pp. 59-81). Springer, Dordrecht.

Binkley, M., Erstad, O., Herman, J., Raizen, S., Ripley, M., Miller-Ricci, M., \& Rumble, M. (2012). Defining twenty-first-century skills. In Assessment and teaching of 21st-century skills (pp. 17-66). Springer, Dordrecht.

Blanchard, K. (2012). 5 Strategies for surfacing and resolving concerns about change. https://leaderchat.org/2020/02/20/5-strategies-for-surfacing-and-resolvingconcerns-about-change/

Blanchard, K. (2018). Leading at a higher level: Blanchard on leadership and creating high performing organizations. FT Press.

Chappell, S., Pescud, M., Waterworth, P., Shilton, T., Roche, D., Ledger, M., ... \& Rosenberg, M. (2016). Exploring the process of implementing healthy workplace initiatives: Mapping to Kotter's leading change model. Journal of Occupational and Environmental Medicine, 58(10), e341e348.

Cheng, B., Wang, M., Yang, S. J., \& Peng, J. (2011). Acceptance of competency-based workplace elearning systems: Effects of individual and peer learning support. Computers \& Education, 57(1), 1317-1333.

Cinite, I., \& Duxbury, L. E. (2018). Measuring the behavioral properties of commitment and resistance to organizational change. The Journal of Applied Behavioral Science, 54(2), 113-139.

Davis, N. (2017). Review of followership theory and servant leadership theory: Understanding how servant leadership informs followership. In Servant Leadership and Followership (pp. 207223). Palgrave Macmillan, Cham.

Dean, Jr, J. W., \& Bowen, D. E. (1994). Management theory and continuous improvement: Improving research and practice through theory development. Academy of management review, 19(3), 392-418.

Dent, E. B., \& Goldberg, S. G. (1999). Challenging "resistance to change." The Journal of applied behavioral science, 35(1), 25-41.

Easdale, D. (2017). Serving from the center: Servant leadership and social capital.

Gandolfi, F., \& Stone, S. (2018). Leadership, leadership styles, and servant leadership. Journal of Management Research, 18(4), 261-269.

Gilley, A., Dixon, P., \& Gilley, J. W. (2008). Characteristics of leadership effectiveness: Implementing change and driving innovation in organizations. Human Resource Development Quarterly, 19(2), 153-169.

Greenleaf, R.K. (1970). The servant as leader. Indianapolis, IN. Robert K. Greenleaf Center.

Halverson, E. R., \& Sheridan, K. (2014). The maker movement in education. 
Harvard Educational Review, 84(4), 495-504.

Greller, W., \& Drachsler, H. (2012). Translating learning into numbers: A generic framework for learning analytics. Journal of Educational Technology \& Society, 15(3), 42

Haque, M. D., TitiAmayah, A., \& Liu, L. (2016). The role of vision in organizational readiness for change and growth. Leadership \& Organization Development Journal.

Ho, J. M., Salleh, H., \& Chua, P. H. (2019). Local evidence synthesis on school change management: Volume 2.

Hosseini, S., Kees, A., Manderscheid, J., Röglinger, M., \& Rosemann, M. (2017). What does it take to implement open innovation? Towards an integrated capability framework. Business Process Management Journal.

Howard, P., O'Brien, C., Kay, B., \& O'Rourke, K. (2019). Leading educational change in the 21st century: Creating living schools through a shared vision and transformative governance. Sustainability, 11(15), 4109.

Isern, J., \& Pung, C. (2007). Driving radical change. McKinsey Quarterly, 4, 24.

Jacob, W. J., \& Gokbel, V. (2018). Global higher education learning outcomes and financial trends: Comparative and innovative approaches. International Journal of Educational Development, 58, 5-17.

Kasworm, C. E., Rose, A. D., \& Ross-Gordon, J. M. (2010). Handbook of adult and continuing education. American Association for Adult and Continuing Education. Los Angeles: SAGE.

Kotter, J. P. (2012). Leading change. Harvard business press.

Kurtz, D. L., \& Berston, S. (2019). Contemporary business. John Wiley \& Sons, Incorporated.

Kuo, T. H. (2011). How to improve organizational performance through learning and knowledge? International Journal of Manpower, 32(5/6), 581-603.

Manning, K. (2017). Organizational theory in higher education. Routledge.

Manuti, A., Pastore, S., Scardigno, A. F., Giancaspro, M. L., \& Morciano, D. (2015). Formal and informal learning in the workplace: a research review. International journal of training and development, 19(1), 1-17.

Markovic, M. R., \& Salamzadeh, A. (2018). The importance of communication in business management. Business Management, Entrepreneurship, and Entrepreneurial Tendencies.

Page, L., \& Schoder, J. (2019). Making change last: leadership is the key. Journal of Business Strategy.

Putnam, R. (2001). Social capital: Measurement and consequences. Canadian journal of policy research, 2(1), 41-51.

Rajan, R., \& Ganesan, R. (2017). A critical analysis of John P. Kotter's change management framework. Asian Journal of Research in Business Economics and Management, 7(7),

181-203.

Russell, R. F., \& Stone, A. G. (2002). A review of servant leadership attributes: Developing a practical model. Leadership \& Organization Development Journal.

Şahin, F., Gürbüz, S., \& Șeșen, H. (2017). Leaders' managerial assumptions and transformational leadership: the moderating role of gender. Leadership \& Organization Development Journal.

Shirey, M. R. (2013). Lewin's theory of planned change as a strategic resource. JONA: The Journal of Nursing Administration, 43(2), 69-72.

Sousa, M., \& van Dierendonck, D. (2017). Servant leadership and the effect of the interaction between humility, action, and hierarchical power on follower engagement. Journal of Business Ethics, 141(1), 13-25. 
Steiner, C. M., Albert, D., \& Heller, J. (2007). Concept mapping as a means to build e-learning. Adult principles of effective e-learning, 59-111.

Thoms, C. L., \& Burton, S. L. (2016). Learning, development, and training: The influence of synergies through educational evolution. International Journal of Adult Vocational Education and Technology (IJAVET), 7(4), 85-104.

Uhl-Bien, M., \& Arena, M. (2018). Leadership for organizational adaptability: A theoretical synthesis and integrative framework. The Leadership Quarterly, 29(1), 89-104.

Webber, C. F., \& Scott, S. (2008). Evidence-based change management development: The 4L framework. Journal of Educational Administration.

Woodward, S., \& Hendry, C. (2004). Leading and coping with change.Journal of Change Management, 4(2), 155-183.

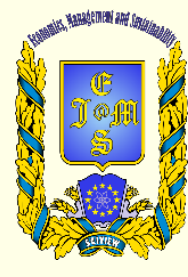

(c) 2016-2020, Economics, Management and Sustainability. All rights reserved.

This open access article is distributed under a Creative Commons Attribution (CC-BY) 4.0 license.

Share - copy and redistribute the material in any medium or format Adapt - remix, transform, and build upon the material for any

purpose, even commercially.

The licensor cannot revoke these freedoms as long as you follow the license terms.

Under the following terms:

Attribution - You must give appropriate credit, provide a link to the license, and indicate if changes were made.

You may do so in any reasonable manner, but not in any way that suggests the licensor endorses you or your use.

No additional restrictions

You may not apply legal terms or technological measures that legally restrict others from doing anything the license permits.

Economics, Management and Sustainability (ISSN: 2520-6303) is published by Scientific Publishing House "CSR",

Poland, EU and Scientific Publishing House "SciView", Poland

Publishing with JEMS ensures:

- Immediate, universal access to your article on publication

- High visibility and discoverability via the JEMS website

- Rapid publication

- Guaranteed legacy preservation of your article

- Discounts and waivers for authors in developing regions

Submit your manuscript to a JEMS at http://jems.sciview.net or submit.jems@sciview.net 